\title{
CULTURA JURÍDICA E EDUCAÇÃO PROFISSIONAL: ANÁLISE DOS DISCURSOS PROFERIDOS PELO DEPUTADO FRANCISCO MENDES PIMENTEL NO TRÂMITE DA LEI ESTADUAL 203/1896
}

\author{
LEGAL CULTURE AND PROFESSIONAL EDUCATION: ANALYSIS OF SPEECHES \\ OFFERED BY THE DEPUTY FRANCISCO MENDES PIMENTEL IN THE PROCESS \\ OF STATE LAW 203/1896
}

\section{Débora Castro ALVES; Irlen Antônio GONÇALVES1}

${ }^{1}$ Centro Federal de Educação Tecnológica de Minas Gerais - CEFET-MG, Departamento de PósGraduação em Educação Tecnológica, Brasil, dboracastroalves@yahoo.com.br; irlen@terra.com.br

\author{
ARTICLE INFO \\ Article history: \\ Received 2018-07-10 \\ Accepted 2019-06-17 \\ Available online 2019-06-17
}

Palavras-chave: Cultura Jurídica. Discurso Político. Francisco Pimentel.

Keywords: Juridical Culture. Political speech. Francisco Pimentel.

RESUMO: O objetivo deste estudo é analisar a presença da cultura jurídica nas discussões que levaram à aprovação da Lei 203, de 18 de setembro de 1896, Lei que tratava do ensino profissional primário no Estado de Minas Gerais. Analisou-se, especificamente, os discursos proferidos pelo deputado Francisco Mendes Pimentel no trâmite da citada Lei, pelo fato deste deputado ter sido o criador do projeto e em razão desse parlamentar ser bacharel em Direito, formado pela Faculdade de Direito de São Paulo. Para realizar a análise do discurso foi utilizada a teoria do Discurso Político proposta por Patrick Charaudeau e o conceito de cultura jurídica defendido por Ricardo Marcelo Fonseca. Trata-se de pesquisa bibliográfica e documental. As fontes utilizadas foram os anais do congresso legislativo mineiro disponibilizados no site do Arquivo Público Mineiro. Constatou-se que o deputado Francisco Mendes Pimentel, além de utilizar várias técnicas argumentativas próprias do discurso político, fez com que os saberes jurídicos por ele aprendidos na Academia circulassem no Parlamento por meio da discussão do projeto de Lei que culminou na aprovação da Lei 203, de 18 de setembro de 1896.

ABSTRACT: The purpose of this study is to analyze the presence of legal culture in the discussions that led to the approval of Law 203, 09/18/1896, law that dealt with primary vocational education in the State of Minas Gerais. Specifically, the speeches given by Deputy Francisco Mendes Pimentel in the process of the said Law were analyzed by the fact that this deputy was the creator of the project and because he was a law graduate, graduated from the Faculty of Law of São Paulo. In order to carry out the discourse analysis, the Political Discourse theory proposed by Patrick Charaudeau and the concept of legal culture defended by Ricardo Marcelo Fonseca were used. This is a bibliographical and documentary research. The sources used were the annals of the Minas Gerais legislative congress made available on the Arquivo Público Mineiro website. It was found that Deputy Francisco Mendes Pimentel, in addition to using various argumentative techniques specific to political discourse, made the legal knowledge he learned at the Academy circulated in Parliament through a discussion of the bill that culminated in the adoption of Law 203, 09/18/1896. 
introdução

A proposta deste artigo é, com base na teoria do discurso político apresentada por Patrick Charaudeau e no conceito de cultura jurídica apresentado por Ricardo Marcelo Fonseca, analisar parte do discurso político proferido por Francisco Mendes Pimentel nas discussões que levaram à aprovação da Lei estadual 203, de 18 de setembro de 1896. Escolheu-se analisar os discursos desse deputado pelo fato de ter sido ele quem elaborou o projeto que deu origem à citada Lei e, também, pelo fato do já referido deputado ser bacharel em Direito.

A partir de uma análise multidisciplinar (Educação, Direito e História), pretende-se demonstrar que o pensamento jurídico, por meio do discurso político, esteve presente nas discussões parlamentares que levaram à aprovação da Lei 203, de 18 de setembro de 1896, que tratou da educação profissional primária em Minas Gerais. Primeiramente, serão apresentadas breves considerações sobre o ensino jurídico no Brasil e o conceito de cultura jurídica utilizado neste trabalho. Após, serão apresentadas considerações acerca da teoria do Discurso Político, de Patrick Charaudeau. No último tópico, será realizada uma análise de parte do discurso proferido pelo deputado Francisco Mendes Pimentel nas discussões legislativas que levaram à aprovação da Lei estadual 203, de 18 de setembro de 1896.

\section{CULTURA JURÍDICA}

Somente a partir do ano de 1821 passou-se a ter normas editadas no território brasileiro, essas normas eram proclamadas pelo Príncipe Regente. (FERREIRA, 2012). Até o ano de 1827, os bacharéis em Direito que existiam no Brasil tiveram a sua formação na Universidade de Coimbra. No interregno entre 1577 a 1822, 2.464 estudantes brasileiros se formaram naquela universidade portuguesa. (MAROCCO, 2011). Já no período compreendido entre os anos 1776 a 1830, período em que se bacharelaram 522 pessoas, 389 eram bacharéis em Direito, o que corresponde a 78,7\% dos graduados. (FERREIRA, 2012).

Aduz Eduardo Oliveira Ferreira (2012) que o liberalismo, a Revolução Francesa e o Enciclopedismo foram ideologias e teorias ensinadas aos estudantes brasileiros em Coimbra e, quando esses estudantes retornaram ao Brasil, quiseram colocar essas ideias em prática e, dessa forma, auxiliaram na Revolução Pernambucana, Inconfidência Mineira e Proclamação da República.

Para Plínio Barreto (1922) quando o Brasil se tornou independente era "uma terra sem cultura jurídica", pois apenas uma parte ínfima da população, que fazia parte dos abastados, tinha condições de ir até Portugal para fazer o curso de Direito. Para o autor, mesmo aqueles que se formaram em Direito não tinham condições de aplicar essa ciência em uma terra em que o ambiente não era apropriado e a maioria das pessoas eram analfabetas. Aduz o autor: 
Não há ciência que se desenvolva sem ambiente apropriado, e o de uma colônia onde mal se sabia ler não é, com certeza, o mais adequado para o crescimento de uma disciplina, como a de direito, que supõe um estado de civilização bem definido nos seus contornos e bem assentado nos seus alicerces. (BARRETO, 1922, p. 9).

Esse problema de não haver um ambiente propício para o desenvolvimento das Ciências Jurídicas perdurou até o ano de 1827 quando, por meio de uma Carta de Lei, foram criados os cursos jurídicos no Brasil. Esse documento dizia que um curso deveria ser localizado na cidade de Olinda e, o outro, na cidade de São Paulo. Também tratava das matérias que deveriam ser ensinadas no decorrer do curso. Segundo Eduardo Bittar (2006) a criação dos cursos jurídicos no Brasil proporcionou que fosse desenvolvida uma cultura jurídica brasileira, nas palavras do autor:

A fundação dos cursos de Direito no Brasil, com estatutos redigidos pelo Visconde da Cachoeira e com duas sedes, uma em Olinda, outra em São Paulo, além de retratar uma necessidade do Império, tornava o Brasil capaz de produzir conhecimentos, de formar seu próprio povo dentro da cultura erudita de além-mar, a exemplo dos centros exportadores de saber, quais Coimbra, Paris, Montepellier e Bolonha. Implantados os cursos jurídicos, estar-se-iam abrindo oportunidades para o preparo e a instrução das elites para o exercício do poder, independentemente de qualquer vinculação ou constrição advindos dos países europeus. (BITTAR, 2006, p. 105).

De acordo com o alegado pelo autor supracitado, um curso de Direito localizado no território nacional permitiria que fosse criado um pensamento jurídico brasileiro com base na realidade brasileira. No mesmo sentido é o pensamento de André Peixoto de Souza (2010) que afirma que a criação das Faculdades de Direito no Brasil permitiu a formação de uma cultura jurídica na fase do Império e proporcionou que os bacharelados naquelas Academias pudessem compor os quadros políticos nacionais. Para ele "a nova formação jurídica produz uma geração de profissionais que estarão sendo recebidos no parlamento para dar conta dos assuntos políticos, mas agora libertos daquela tradição portuguesa, registrando uma nova cultura em substituição à dominante. " (SOUZA, 2010, p. 91). Nesse sentido, continua o autor:

Num contexto em que o Brasil precisava se organizar como Estado soberano e afirmar valores de nacionalidade, era mister definir aqueles que iriam dirigir o futuro do novo País, pois os advogados atuavam tanto em questões peculiares ao direito e à justiça quanto na política, bem como na tarefa de redação das leis que substituiriam gradativamente a legislação portuguesa ainda em vigor. (SOUZA, 2010, p. 92).

Os estudos de Eduardo Bittar (2006) são no mesmo sentido, pois, para esse autor, as Faculdades de Direito foram essenciais para a formação dos poderes oriundos do Estado. Bittar (2006) também alega que essas Faculdades pretendiam, muito mais, criar políticos do que formar profissionais para atuação em áreas estritamente jurídicas:

A academia, então, torna-se um laboratório para os aprendizes do poder, local de reprodução das diferenças sociais e de fermentação das elites jurídicas e administrativas do Estado brasileiro. O engajamento estudantil nos atos políticos do 
país, a vocação acadêmica pelos atos do poder, a atenção dos holofotes estudantis para as políticas imperantes traçam, desde o início, o perfil ativista da Academia de Direito na constituição dos poderes estatais; é isso, historicamente, prova de que o ambiente acadêmico servia pouco para a exclusiva ilustração intelectual e formação profissional estrita, e servia muito para a construção e projeção de figuras do cenário político nacional. (BITTAR, 2006, p. 108)

O próprio Estatuto elaborado por Visconde de Cachoeira, documento anexo à Carta de Lei de 1827, dizia, expressamente, que um dos objetivos do curso de Ciências Jurídicas era formar pessoas para compor os cargos políticos do país. Interessante é o fato de o Dicionário do Brasil Imperial definir as Faculdades de Direito como um local de formação de políticos, vejamos:

Faculdades de Direito. Consideradas por Nabuco as 'ante-salas da Câmara' centros por excelência de formação de políticos e da administração imperial - as faculdades de direito foram, junto com as de medicina, os primeiros cursos de nível superior criados no Brasil (...) criadas à semelhança de Coimbra (...) as faculdades de direito brasileiras introduziram em seus currículos algumas modificações importantes (...). Isso evidencia como mostram seus estatutos, que o objetivo da criação dos cursos jurídicos era não só a formação de juristas, mas de advogados, deputados, senadores, diplomatas e quadros para a burocracia estatal, condição essencial para a constituição de um Estado de forma independente. (...) A Faculdade de Direito de São Paulo (...) continuou marcada pela militância política stricto sensu e pelo exercício do jornalismo. Foi dos bancos escolares paulistas da década de 1870 que saíram os bacharéis que doravante se destacariam pela militância política, como Rui Barbosa, que mais tarde diria: 'No estudo do Direito, o mundo acadêmico e o mundo político se penetram mutuamente'. (VAINFAS, 2002, p. 256-257, apud, SOUZA, 2010, p. 90).

Evidenciando essa noção de que as Faculdades de Direito formavam os futuros agentes políticos há pesquisas que demonstram a forte presença dos bacharéis nos cargos políticos durante o Império e a Primeira República. Estudos realizados por Francisco Teotônio Simões Neto (1983) revelaram que no período compreendido entre os anos de 1826 a 1958 quase $60 \%$ dos membros do poder legislativo eram bacharéis em Direito. Entre os anos 1880 a $1889,65,5 \%$ dos deputados federais possuíam formação jurídica. Na Primeira República, período compreendido entre 1889 a 1930, 44,3\% dos integrantes da Câmara eram formados em Direito.

Irlen Antônio Gonçalves (2015) aponta que, em relação ao poder executivo, dos treze presidentes da Primeira República, dez eram bacharéis em Direito. Em Minas Gerais, no mesmo período, doze entre os quinze presidentes eram bacharéis em Direito.

Esses dados evidenciam que os bacharéis, durante o Império e a Primeira República, marcaram presença nos poderes executivo e legislativo, além, é claro, do poder judiciário. Como já afirmado, o escopo deste estudo é analisar como os pensamentos jurídicos aprendidos na Academia forma relevantes nos discursos apresentado pelo deputado mineiro Francisco Mendes Pimentel para a aprovação da Lei estadual 203, de 18 de setembro de 
1896. Para isso, é necessário apresentar o conceito de cultura jurídica que será tomado como base para a realização da análise.

Utilizaremos o conceito de cultura jurídica defendido por Ricardo Marcelo Fonseca, para esse autor "a cultura jurídica é aquilo que circula funciona e produz efeitos dentro de um determinado contexto histórico e social". (FONSECA, 2008, p.61). A cultura jurídica brasileira vai sendo construída em um contexto de tensão entre o velho e o novo. Há as tradições portuguesas que ainda prevaleciam no Brasil, principalmente porque, mesmo após a independência, a princípio, continuou-se utilizando os regramentos portugueses e também devido ao fato de que até o ano de 1827 não existia nenhum curso de Direito no país e, mesmo com a criação das Faculdades, os professores possuíam formação em Portugal. Somente na segunda metade do Século XIX, a maioria dos lentes, nomenclatura dada aos professores da época, tinha formação nas faculdades brasileiras.

De acordo com Fonseca (2005) para entender a cultura jurídica é necessário entender que o Direito não é apenas instrumento de repressão social, mas é também algo que é construído historicamente e que está arraigado aos valores que são relevantes em uma determinada sociedade em um determinado período histórico.

$\mathrm{Na}$ análise dos anais, buscou-se identificar como os saberes jurídicos aprendidos na Faculdade de Direito de São Paulo, local de formação do deputado Francisco Mendes Pimentel, foram utilizados na argumentação desse parlamentar para fazer com que o seu projeto de Lei fosse aprovado pelos demais membros do parlamento mineiro. Analisou-se o quanto as ideias jurídicas circularam por meio da exposição de um bacharel em Direito na Câmara dos Deputados. Além da cultura jurídica, também será analisado o discurso político do parlamentar com base na teoria proposta por Patrick Charaudeau que será tratada no próximo tópico.

\section{$3 \quad$ DISCURSO POLÍTICO}

Conforme já dito anteriormente, nesse estudo será analisado o discurso proferido por um deputado mineiro, qual seja, Francisco Mendes Pimentel. Trata-se de um discurso político uma vez que o citado discurso foi realizado no Congresso Legislativo Mineiro e tinha o escopo de fazer com que o projeto de Lei, que era de autoria do citado deputado, fosse aprovado por seus pares. A teoria utilizada para a realização dessa análise é a apresentada por Patrick Charaudeau na obra O Discurso Político.

Patrick Charaudeau, nascido na França, criou uma Teoria para a Análise do Discurso político. Atualmente, é professor da Universidade de Paris Nord, sendo autor de vários livros. Charaudeau enxerga o discurso político como um procedimento capaz de influenciar a sociedade. O autor considera a política como uma instância que, por sua vez, tem sua atuação condicionada a atender os anseios de uma outra instância, a instância cidadã. Nesse caminho, 
o discurso político deve adotar meios para influenciar o auditório que deseja persuadir e, para tanto, a linguagem, seja ela verbal, ou não, é essencial. (CHARAUDEAU, 2017).

A Linguagem só faz sentido se for considerada em seu contexto. Linguagem e ação estão totalmente imbricadas. A linguagem provém de uma pessoa que só a expressa porque existe um outro ser a quem ela é dirigida. Essa linguagem não é neutra, ela busca fazer com que o outro pense assim como o emissor pensa, mas o receptor pode ter seus próprios pensamentos já construídos o que levará a um gerenciamento das expressões, o que se fará por meio do princípio da regulação. Acerca dessa relação, afirma Charaudeau: (2017, p. 17):

[...] o projeto de influência adquire certo poder de ação. Da mesma forma, o sujeitoalvo é colocado numa posição de dominado, o sujeito de autoridade em uma posição dominante e os dois em uma relação de poder. Assim, pode-se dizer que todo ato de linguagem está ligado à ação mediante as relações de força que os sujeitos mantêm entre si, relações de força que constroem simultaneamente o vínculo social.

No caso desse estudo, a linguagem utilizada pelo deputado tinha a pretensão de fazer com que os demais deputados fossem persuadidos, comprassem a sua ideia e aprovassem o projeto de lei por ele proposto. O público alvo desse deputado, o seu auditório, eram os demais deputados uma vez que ele dependia destes para que o seu projeto se tornasse Lei e entrasse em vigor.

A ação política tem a função de organizar a sociedade, ela também permite que a sociedade tome decisões de forma coletiva. Entretanto, para que essa decisão coletiva ocorra, faz-se necessário que os membros dessa coletividade se reúnam a fim de elaborarem um projeto que tenha como escopo algo que irá beneficiar os membros dessa sociedade de forma coletiva. Este projeto será elaborado após discussões coletivas e depois que os indivíduos tenham escolhido um representante. Este, por sua vez, deverá colocar em prática o projeto elaborado pela coletividade e prestar contas dos seus atos. Havendo isso, haverá um controle da ação política. (CHARAUDEAU, 2017).

Para Charaudeau (2017) existem duas instâncias, a instância política e a instância cidadã. Aquela tem como dever praticar a ação política e o faz mediante delegação da instância cidadã, que deverá escolher quais serão os representantes da instância política. Trata-se de uma "dominação legítima" tal como pregado por Max Weber. A instância política age dentro do possível para atender os desejos da instância cidadã, contudo, nessa ação política, os representantes, por meio da persuasão, tentam convencer a coletividade que aquilo que eles pretendem será o melhor para a sociedade. (CHARAUDEAU, 2017).

Francisco Pimentel, no caso em questão, é o representante do povo que busca fazer com que os interesses da coletividade sejam efetivos por meio do seu projeto de lei, que tem a finalidade de garantir o ensino profissional primário à população. 
Há quatro setores de interação que auxiliam na organização da ação política e para que esta atinja as suas finalidades, esses setores são o jurídico, econômico, midiático e político. Cabe ao jurídico dirimir os conflitos havidos no seio da sociedade; ao midiático, gerenciar as informações que são passadas aos indivíduos; ao econômico, a regulação do mercado e, ao político "estabelecer regras para a governança, distribuindo tarefas e responsabilidades mediante a instauração das instâncias legislativas e executivas". (CHARAUDEAU, 2017, p. 28).

Para Charaudeau (2017, p. 32) "toda fala política é, evidentemente, por definição, um fato social". Para o autor, não existe política se não houver um discurso, a linguagem é o principal fator que orienta a ação, sendo esta um dos principais fatores da política. Nesse sentido, afirma o autor:

O discurso político não esgota, de forma alguma, todo o conceito político, mas não há política sem discurso. Este é constitutivo daquela. A linguagem é o que motiva a ação, a orienta e lhe dá sentido. A política depende da ação e se inscreve constitutivamente nas relações de influência social, e a linguagem, em virtude do fenômeno de circulação dos discursos, é o que permite que se constituam espaços de discussão, de persuasão e de sedução nos quais se elaboram o pensamento e a ação políticos. A ação política e o discurso político estão indissociavelmente ligados, o que justifica pelo mesmo raciocínio o estudo político pelo discurso. (CHARAUDEAU, 2017, p. 39).

Há três lugares onde o pensamento político é construído: um lugar onde há a criação do pensamento jurídico, um lugar relacionado à comunicação desse pensamento e um lugar destinado à produção de comentários. O primeiro, onde há a criação do pensamento jurídico, para Charaudeau (2017, p. 40) "é o resultado de uma atividade discursiva que procura fundar um ideal político em função de certos princípios que devem servir de referência para a construção das opiniões e dos pensamentos". É por meio desse sistema, com base nos pensamentos apresentados, que é possível discernir as ideias presentes em cada pensamento. O segundo, o discurso como ato de comunicação, consiste nos discursos que visam buscar o maior número de adesão possíveis. Nesta fase que os procedimentos retóricos são utilizados a fim de convencer o maior número de pessoas possível. O terceiro trata-se de um discurso de comentário acerca de uma ação política, mas que não visa uma ação, tratase apenas de um comentário. (CHARAUDEAU, 2017).

O parlamento é o local de comunicação do pensamento no caso da análise do discurso dos anais. É o lugar em que os parlamentares tinham total liberdade para expor tudo aquilo que julgavam conveniente.

No domínio político, a noção de legitimidade também é importante. A legitimidade é o direito de exercer uma ação, um poder específico. Ela ocorre quando outros indivíduos reconhecem que um determinado sujeito tem o direito de produzir uma ação específica. Essa legitimidade, que permite que a instância política faça uso de todos os mecanismos possíveis 
para manter a ordem, só persiste enquanto a instância cidadã a reconhece. (CHARAUDEAU, 2017).

Aqui, a noção de soberania é relevante, pois, a instância política só poderá agir se legitimada pelo povo, pela instância cidadã, aduz Charaudeau (2017, p. 69) "a soberania está, portanto, sob tutela, mas ela é, ao mesmo tempo, o próprio poder tutelar. Efetivamente, é esse poder que investiu o soberano e fez dele seu depositário, obrigando-o a aderir a ele próprio, na verdade, a se fundir nele mesmo. " A soberania vem acompanhada da responsabilidade, aquele que foi legitimado pela instância cidadã deverá prestar contas dos seus atos àquela.

O político deve utilizar da persuasão para convencer os indivíduos das suas propostas e valores. Para Charaudeau (2017, p. 80) "o que caracteriza essa identidade discursiva seja um Eu-nós, uma identidade singular-coletivo." Em sua identidade singular o político fala como portador das vozes do povo, é o escolhido para defender valores e ideais de terceiros. $\mathrm{O}$ discurso do político dependerá do público a que se destina, quando se tratar de uma elite, buscará convencê-la de que as alianças com o seu partido para que os seus projetos sejam colocados em prática, serão úteis e vantajosas. Quando se tratar das massas, tentará despertar uma paixão em relação ao homem que profere o discurso ou em relação ao projeto apresentado, trata-se da busca por uma dominação legítima. (CHARAUDEAU, 2017).

Charaudeau (2017) também trata das condições da argumentação. Estas têm por escopo demonstrar que os argumentos se baseiam em questões racionais. Não se busca a verdade, mas apenas a veracidade, aquilo que o orador toma para si como verdade e tenta persuadir o público acerca disso. Os argumentos poderão se basear na força das crenças compartilhadas, no peso das circunstâncias, na vontade de agir, no risco, na autoridade, com analogia de fatos pretéritos e qualquer outro artifício que busque a adesão dos indivíduos. (CHARAUDEAU, 2017).

Há também os procedimentos enunciativos, que são a enunciação elocutiva, enunciação alocutiva e enunciação delocutiva. A enunciação elocutiva demonstra a opinião do orador, por isso utiliza pronomes pessoais, advérbios e qualificativos capazes de demonstrar que aquela fala reflete a sua opinião. Quando o pronome "nós" é utilizado, demonstra-se uma certa solidariedade, no sentido de que o orador comunga dos mesmos objetivos do povo para adotar os procedimentos necessários a fim de coloca-los em prática. (CHARAUDEAU, 2017).

$\mathrm{Na}$ enunciação alocutiva serão utilizados pronomes pessoais em segunda pessoa. Busca-se trazer o interlocutor para o discurso. Nas palavras de Charaudeau (2017, p. 176):

A enunciação alocutiva é expressa com a ajuda de pronomes pessoais de segunda pessoa, igualmente acompanhados de verbos modais, de qualificativos e de diversas denominações que revelam, ao mesmo tempo, a implicação do interlocutor, o lugar que the designa o locutor e a relação que se estabelece entre 
eles [...]Essa maneira de implicar o interlocutor tem, portanto, o efeito de fabricar, em contrapartida, determinada imagem do locutor.

$\mathrm{Na}$ enunciação delocutiva o orador apresenta um discurso como se fosse verdade, o auditório passa a ver o orador como um soberano, o portador da verdade. O orador poderá fazer uso de todos esses instrumentos ao mesmo tempo, ou apenas de alguns, dependerá da finalidade que almeja atingir. (CHARAUDEAU, 2017).

A forma como o orador apresentará o seu discurso dependerá do propósito deste. 0 que será dito não se trata de um tema livre, mas sim do escopo do discurso. De acordo com Charaudeau (2017, p. 189) o discurso político "concerne a tudo o que toca à organização da vida em sociedade e ao governo da coisa pública". Busca-se algo que favoreça a instância política e a instância cidadã, uma vez que esta é a que dá legitimidade àquela para que atue em prol do bem comum. Considerando que todas as sociedades são compostas por pessoas diferentes, o discurso político deve ser um discurso que elege um valor que será aceito por todas as pessoas, apesar da reconhecida diversidade existente entre elas. (CHARAUDEAU, 2017).

Conforme exposto, Charaudeau apresenta uma teoria de análise para um discurso específico, o discurso político. Essa teoria será utilizada para a análise dos anais que será realizada no próximo item.

\section{ANÁLISE DOS ANAIS}

A Lei 203, de 18 de setembro de 1896, tinha como finalidade organizar o ensino profissional primário, em Minas Gerais. A citada Lei possuía apenas 27 artigos. Seu texto tratou dos Institutos dos educandos artífices, do plano de ensino, das oficinas, do pessoal administrativo, dos professores, do regime escolar, dentre outras disposições. (MINAS GERAIS, Lei 203, 1896).

O Projeto de lei que deu origem à Lei em comento recebeu o número 169 e foi proposto por Francisco Mendes Pimentel. Esse parlamentar iniciou a discussão do projeto falando da constitucionalidade deste e, para fundamentar a sua fala, citou os dispositivos constitucionais que autorizavam a propositura do projeto. Esse ato claramente demonstra a preocupação do deputado em que o projeto, por ele elaborado, estivesse em consonância com a Lei maior, qual seja, a primeira Constituição da República:

O § 27 do art. 30 da nossa Constituição autoriza o Congresso a promover o desenvolvimento da educação pública, das artes e da indústria no Estado, e outro não é o um visado pelo projecto que elaborei e que ora se acha em debate. Além disto, além do texto claro e expresso da nossa Carta Fundamental, eu me julgo exonerado e desobrigado de entrar em maiores explanações sobre o ponto da constitucionalidade do projeto, pois que falo para uma assembléia que até hoje não tem regateado auxilio a associações que se têm fundado ou estabelecido no Estado com o intuito de difundir o ensino técnico primário. (PIMENTEL,1896, p.13) 
Pimentel cita, inclusive, o dispositivo constitucional que autorizava que o Congresso criasse normas cujo escopo fosse a propagação da educação pública. Percebe-se aqui a circulação de saberes jurídicos aprendidos na Faculdade de Ciências Jurídicas, a noção de que a Constituição era a Lei Maior e que os demais atos normativos deveriam estar de acordo com o seu texto era algo ensinado nas disciplinas Direito Público e Análise da Constituição do Império que, de acordo com a Carta de Lei de 11 de agosto de 1827, deveriam ser ensinadas no primeiro ano do curso.

O parlamentar também falou da necessidade e da utilidade para o Estado de que houvesse a regulamentação do ensino profissional, pois considerava que essa modalidade de ensino auxiliaria na construção de uma independência econômica:

Sr. Presidente, quanto à vantagem, à utilidade e mesmo à necessidade da organização do ensino profissional em seu grau primário, é essa uma ideia de há muito vencedora e é unicamente para lastimar que até hoje não tenhamos encarado de frente questão de tanto tomo. (Apoiados). Para efetividade autonômica de uma nacionalidade não basta que um povo se tenha constituído politicamente e que em seu seio se tenha operado a emancipação civil; é necessário mais, é imprescindível organizar a riqueza pública, fundar a independência econômica. (PIMENTEL,1896 p.14).

A preocupação em organizar o ensino profissional demonstra que o parlamentar, de acordo com o proposto por Charaudeau, tem uma preocupação em beneficiar a instância cidadã com a criação de um projeto que leve essa modalidade de educação para a coletividade. Ademais, é notório que o deputado entende que a organização desse ensino, por meio de uma Lei, era dever dos parlamentares e que há um descontentamento por parte do deputado em razão do assunto ainda não ter sido tratado pela legislação.

Pimentel considerava que o fato de não haver fábricas e indústrias no Brasil, na década de 90 do século XIX, fazia com que o país ainda se tornasse dependente da metrópole. O deputado cita França como exemplo, argumenta que esse país investiu nas indústrias para garantir o seu desenvolvimento econômico.

Os próprios estadistas franceses da terceira república não se deixaram dementar pelas inspirações ardentes do patriotismo apaixonado e vulcânico que ali reclama a revanche para desagravo, para desopróbrio, para desafronta nacional. Eles não perderam a calma e a clarividência que é a grande qualidade dos homens de Estado, e, compreendendo que a época não é mais da caserna e sim da oficina, empenharam todo o seu esforço em soerguer a França desenvolvendo-lhe as forças econômicas. (Muito bem). Um dos homens mais notáveis desse país, Jules Ferry, disse em um os seus vigorosos discursos: "Sobre o campo da batalha industrial como sobre o outro as nações podem cair e perecer; sobre este campo de batalha como sobre o outro pode-se ser surpreendido. É este grande perigo que o ensino profissional deve evitar; não há interesse nacional mais considerável e eu posso dizer sem temor de desmentido: neste momento levantar a oficina é levantar a Pátria" (Apoiados). Esse mesmo estadista francês quando Ministro da Instrução e Belas Artes notava no seu relatório de outubro de 1891: "Por um impulso tão espontâneo quanto irresistível as escolas primarias superiores tendem a se revestir do caráter de escolas profissionais; a escola; a escola transforma-se em oficina e o 
aluno em aprendiz". E Srs. Deputados, além deste lado econômico em que não mais insistirei, tem o problema ora sujeito a vossa discussão e deliberação uma face política que não pode ser desconhecida e menos ainda desprezada. (PIMENTEL, 1896, p.14-15)

Nessa parte do discurso do parlamentar percebe-se que foram exploradas algumas técnicas argumentativas propostas por Charaudeau, como o peso das circunstâncias, a vontade de agir e a analogia. O deputado utiliza em seu discurso argumentos que têm como base a situação atual do país naquela época, qual seja, uma nação ainda não desenvolvida economicamente quando comparada a outras, ou seja, faz uso do peso das circunstâncias para levar seus pares ao convencimento. Utiliza da analogia ao citar a França e faz uso dos conhecimentos de uma pessoa de prestígio naquele país, Jules Ferry. Também percebe-se no discurso que há uma vontade de agir no sentido de fazer com que o país se desenvolva economicamente.

Pimentel entende que o não investimento em educação popular contrariava os ideais republicanos, que pregava um governo do povo para o povo:

Nós que pregamos a República como o regime popular por excelência, nós que ou apostolamos a redenção política da nossa Pátria ou a ela prometemos e protestamos servir com fé e com lealdade, nós que em nossas bandeiras partidárias inscrevemos o velho lema, a velha divisa do governo do povo pelo povo, nós que só do povo tiramos toda a força que aqui nos congrega e que aqui nos mantém, nós, digamo-lo assim com franqueza e digamo-lo com verdade, nós temos bem cumprido o primeiro dos nossos deveres, nós nos temos descurado da verdadeira educação popular. (PIMENTEL, 1896. p. 15).

Aqui, notoriamente há a circulação de saberes e pensamentos jurídicos. A preocupação com os ideais da República demonstra que o deputado considerava relevante que aquilo que era proposto por essa forma de governo, um governo em que houvesse a participação do povo e que existia apenas por causa deste, fosse efetivado. Mais uma vez também é nítida a preocupação em atender aos interesses da instância cidadã.

O deputado também fala da negligência do Estado em proporcionar para os pobres a mesma educação que era proporcionada aos mais abastados:

Para o pobre, para o operário, para o proletário, para o verdadeiro povo, enfim, cessa a educação aos primeiros passos da vida; para o rico, para o abastado, para o protegido, para essa minoria favorecida, o Estado a acompanha com a tutela solícita através do ensino secundário e superior até conferir-lhe um grau científico que social e legalmente a coloca em posição vantajosíssima na competência vital. (Muito bem. Apoiados). (PIMENTEL, 1896, p. 15).

O pensamento jurídico também se encontra presente nessa fala. Ao tratar da desigualdade social há, implicitamente, uma discussão acerca do princípio da igualdade. Esse direito, expressamente contava na Constituição da República de 1891, em seu artigo $72, \S 2$.

O deputado fala, ainda, que chegaria uma hora em que os oprimidos, a camada pobre da população, se voltaria contra os opressores e, para que isso não acontecesse, era 
necessário que fossem adotadas medidas que favorecessem aquela camada, sendo que a educação do operário para o trabalho cumpriria essa função:

É preciso que nós homens públicos e portanto previdentes procuremos desde já incorporar o proletariado à nação, é imprescindível que desde já envidemos todo o esforço patriótico para educar o operário na escola do trabalho e do cumprimento dos deveres cívicos, para quando o vagalhão do socialismo atravessar de lado a lado o Atlântico e vier quebrar-se estuante praias brasileiras, o nosso proletariado esteja preparado para exercer os seus direitos e cumprir os seus deveres e não se subverta, não pereça nos vórtices da anarquia, arrastando consigo talvez a própria Pátria. (Apoiados; muito bem, muito bem). (PIMENTEL, 1896, p. 15-16).

O Sr. Francisco M. Pimentel deixou claro a sua preocupação em ensinar aos operários as ideias/pensamentos que ele entendia serem as melhores para que aqueles não simpatizassem e passassem a aderir teses relacionadas ao socialismo e ao anarquismo. Para o parlamentar, a finalidade da escola seria educar para o trabalho e para o cumprimento dos deveres cívicos. Aqui há o uso da enunciação elocutiva quando o deputado usa o pronome "nós" para tentar demonstrar que o dever de incorporar os trabalhadores na República era também dele. $O$ deputado se inclui no discurso e no dever de garantir a instrução como forma de persuadir o seu auditório.

O parlamentar sustentou que nos países cultos, onde os governadores faziam bem os seus papéis, havia um investimento na educação para o trabalho. Citou França e as pessoas que propuseram a criação do ensino técnico primário naquele país e sustentou que aquelas instituições eram subvencionadas pelo Estado Francês e eram consideradas Escolas Modelo. O deputado concluiu a sua fala, a respeito desse assunto, dizendo que naquele país os governantes entenderam que também era preciso governar para o proletariado:

Em França, como v. exc sabe, foram homens do valor de Floquet, Nadaud, Lockroy, Spuller, que em 1878 inauguraram a campanha desde logo vitoriosa e triunfal em prol do ensino técnico primário. Ali as comunas e os departamentos criaram numerosos estabelecimentos desse gênero e de acordo com a especialidade industrial do lugar, e o próprio Estado, o próprio Governo Central, além de subvencionar os institutos comunais e departamentais em virtude da lei de $11 \mathrm{~d}$ dezembro de 1880 , criou e mantêm três estabelecimentos modelos, três escolas tipos e tais são as de Vierzon, de Armentières e de Voiron. Ali os estadistas compreenderam que uma república democrática não tem o direito de aplicar grande parte da fortuna publica em favorecer exclusivamente uma minoria abastada, mas deve dar o maior elastério à educação do proletariado. (Apoiados). (PIMENTEL, 1896, p. 16).

Mais uma vez há a utilização da analogia para usar um país como exemplo e tentar demonstrar que o que ocorreu naquele país também poderia ser aplicado ao Brasil. 0 Deputado ainda citou como exemplo as medidas adotadas na Alemanha e na Prússia. E para fundamentar a apresentação do projeto, fundamentou a sua opinião no trecho do livro do Filósofo da educação, Valentin Latelier, que afirma que o ensino é necessário para o desenvolvimento industrial e para a utilização da ciência: 
Diz o eminente professor da universidade nacional do Chile que o ensino industrial sempre existiu quer nas sociedades organizadas sob o regime das castas - na Índia, no Egito, no Império dos Incas - quer nas corporações medievais de artes e ofícios. $\mathrm{E}$ referindo-se à continuidade ininterrupta de esforços constantes para a propagação do ensino profissional, acrescenta: "O que de novo há nas sociedades cultas é que nestas se faz sistematicamente o mesmo que nas mais atrasadas se faz de modo espontâneo, é que as primeiras substituem pelo ensino científico o ensino empírico ministrado pelas segundas". Diz ainda o pensador chileno: "É grave erro considerar a instrução especial dos povos cultos obra. Dispensável de luxo, quando seus antecedentes históricos estão demonstrando que é essa uma função indispensável sem a qual não se pode utilizar a ciência para o desenvolvimento industrial". Nesse mesmo capítulo ainda assim se exprimo o publicista: "Se os governos das nações cultas se empenham com tanta perseverança em fundar a instrução especial não é com o intuito de invadir o campo da atividade privada. É sim porque estão vendo os seus se povos vencidos nas lutas da indústria sempre que ousam entrar na concorrência antes de adquirido especial preparo científico".(PIMENTEL, 1896 p. 17).

$\mathrm{Na}$ fala do deputado, reiteradamente há menção a doutrinadores estrangeiros e exemplos de outros países a fim de demonstrar que propostas similares as apresentadas por ele tiveram êxito em outros lugares do mundo.

Pimentel informa que, na Cidade de Barbacena, apesar de haverem muitas jazidas aptas a serem exploradas, para que a exploração se efetivasse, foi necessário importar trabalhadores uma vez que os moradores de Barbacena não possuíam o conhecimento necessário para trabalhar nas jazidas. Argumentou que a realização desse ensino era função do Estado e que este não poderia negligenciar nesse sentido. Neste caso, mais uma vez, a argumentação considerou o peso das circunstâncias, qual seja, a realidade de que o Estado não possuía mão de obra qualificada o que fazia com que tivesse que importar mão de obra. Fato que interferia em sua economia uma vez que essa importação era dispendiosa financeiramente.

É perceptível no discurso do deputado que há uma grande preocupação em efetivar a educação para o trabalho. O deputado demonstrou a importância de efetivar uma educação profissional e formar uma mão de obra qualificada brasileira para que o país não precisasse importar profissionais. Percebe-se que a preocupação com a economia do país e com as indústrias foi algo recorrente no discurso do deputado.

A análise dos discursos do parlamentar Francisco Mendes Pimentel demonstra que, por meio desse parlamentar, houve a circulação de pensamentos jurídicos na Câmara dos Deputados, no momento de discussão do Projeto que levou à aprovação da Lei estadual 203, de 18 de setembro de 1896. Também constatou-se que o deputado fez uso de várias técnicas argumentativas típicas do discurso político. 
Por meio do presente estudo constatou-se que a cultura jurídica brasileira passou a ser construída a partir do ano de 1827, quando os cursos jurídicos foram criados no país, pois, anteriormente a esta data a formação em Ciências Jurídicas era possível apenas em outros países, sobretudo em Portugal, local em que se formavam os brasileiros que tinham a pretensão de obter o grau de bacharéis em Direito.

Também ficou claro que vários autores nacionais consideram que a finalidade das Academias de Direito não era apenas formar profissionais para exercerem as atividades jurídicas, mas, também, qualificar profissionais que iriam compor o quadro burocrático do país, o que aconteceu. Pesquisas demonstraram que, além da atuação no poder judiciário, houve uma forte presença dos bacharéis em Direito em cargos dos poderes executivo e legislativo.

Concluiu-se, utilizando o conceito de cultura jurídica e a o teoria da análise do discurso político proposta por Patrick Charaudeau, que o deputado Francisco Pimentel fez com que circulassem no parlamento os saberes jurídicos aprendidos na Faculdade de Direito e que o deputado utilizou de várias técnicas argumentativas típicas do discurso político a fim de convencer os seus pares de que a criação do ensino profissional primário era a decisão mais benéfica, naquele momento, para o Estado de Minas Gerais. 


\section{REFERÊNCIAS}

BARRETO, Plínio. A Cultura Jurídica no Brasil. Imprenta, São Paulo - 1922.

BITTAR, C.B. Eduardo. Estudos sobre Ensino Jurídico: Pesquisa, Metodologia, Diálogo e Cidadania. 2 ed. Ver., modificada, atul. e ampl. - São Paulo: Atlas, 2006.

BRASIL, Carta de Lei de 11 de agosto de 1827. Crêa dous Cursos de sciencias Juridicas e Sociaes, um na cidade de S. Paulo e outro na de Olinda. Acesso em 02 de novembro de 2017. Disponível em http://www.planalto.gov.br/ccivil 03/leis/lim/LIM-11-08-1827.htm

CHARAUDEAU, Patrick. Discurso político. 2 ed. São Paulo: Contexto, 2017. Tradução de Fabiana Komesu e Dílson Ferreira da Cruz.

FERREIRA, Eduardo Oliveira. Os Bacharéis do Direito na História do BRASIL 2012. Disponível em http://www.justocantins.com.br/advocacia-9656-os-bachareis-do-direito-nahistoria-do-brasil.html. Acesso em 30 de outubro de 2017.

FONSECA, Ricardo Marcelo. A formação da cultura jurídica nacional e os cursos jurídicos no Brasil: uma análise preliminar (1854-1879). Cuadernos del Instituto Antonio de Nebrija de Estudios sobre la Universidad, Madri, v. 8, n.1, p. 97-116, 2005.

FONSECA, Ricardo Marcelo. Vias da modernização jurídica brasileira: a cultura jurídica e os perfis dos juristas brasileiros do século XIX. Revista Brasileira de Estudos Políticos, v. 98, p. 257-293, 2008.

GONÇALVES, Irlen Antônio. A retórica discursiva dos bacharéis em direito sobre os projetos de educação profissional. In: VIII Congresso Brasileiro de História da Educação, 2015, Maringá. VIII Congresso Brasileiro de História da Educação: matrizes interpretativas e internacionalização. Maringá: Universidade Federal de Maringá, 2015. v. 1. p. 03-17

MAROCCO, Andréa de Almeida Leite. Educação Jurídica no Brasil: desafios à formação do profissional do Direito no Século XXI. 2011. Dissertação (Mestrado em Direito) - Faculdade de Direito, Universidade Federal de Santa Catarina, Florianópolis, 2011.

MINAS GERAIS. Lei no 203, de 18 de setembro de 1896. Que organiza o ensino técnico profissional primário. Minas Gerais, Ouro Preto, 1895.

PIMENTEL, Francisco Mendes. Anais da Câmara dos Deputados. Imprensa Oficial, Belo Horizonte, 1896.

SIMÕES NETO, Francisco Teotônio. Bacharéis na política e a política dos bacharéis. São Paulo, 1983. São Paulo: Tese (Doutorado em Ciências Sociais) - Faculdade de Ciências Sociais, USP, 1983.

SOUZA, André Peixoto. Direito público e modernização jurídica: elementos para compreensão da formação da cultura jurídica brasileira no século XIX. Curitiba, 2010. 196 f. Tese (Doutorado em Direito) - Faculdade de Direito, Universidade Federal do Paraná, Curitiba, 2010.

VAINFAS, Ronaldo (org.). Dicionário do Brasil imperial. Rio de Janeiro: Objetiva, 2002. 